\title{
Formation of spiritual culture and environmentally responsible human behavior
}

\author{
Asanbek Akmataliev 1,*, Mirlanbek Manashov ${ }^{2}$, Turdukan Abdykaarova ${ }^{2}$, Rustambek \\ Salimov $^{3}$, Samara Karabaeva ${ }^{2}$, and Gulnara Tilenbaeva ${ }^{3}$ \\ ${ }^{1}$ Osh Technological University, 723503, N.Isanov str., 81, Osh city, Kyrgyz Republic \\ ${ }^{2}$ Osh State University, 723500, Lenin Avenue, 331, Osh city, Kyrgyz Republic \\ ${ }^{3}$ Kyrgyz-Uzbek International University named after B.Sydykov, 723500, G.Aitiev str., 27, Osh city, \\ Kyrgyz Republic
}

\begin{abstract}
The spiritual sphere of the society is a system of relations between people, reflecting the spiritual and moral life of a society, represented by such subsystems as culture, science, religion, morality, ideology, art. The significance of the spiritual sphere is determined by its most important, priority function of determining the value-normative system of a society, which, in its turn, reflects the level of development of public consciousness and the intellectual and moral potential of a society as a whole. The relevance of the research topic is determined by the sociocultural changes taking place in a society associated with the formation of a new type of sociality in Kyrgyzstan. In a society that has moved to a different stage of socio-historical development, the role of the spiritual sphere of society changes significantly. In the conditions of the existence of worldview pluralism and the complication of social reality, the need to reflect on society as a "field" for the implementation of various intentions of spiritual life is actualized. The formation of a new social reality of a society in the process of transition to market relations is associated with negative processes of spiritual impoverishment of citizens, gradually forgetting about their historical roots.
\end{abstract}

\section{Introduction}

The study of the spiritual and moral life of a society presently supposes the allocation of its structural elements. Such elements are called forms of social consciousness. Moral, religious, political, scientific, aesthetic consciousness are some of social consciousness. These forms determine the corresponding subsystems of the spiritual sphere of a society, differing from each other, not only in the content and method of cognizing their object, but also in the time of occurrence in the process of development of a society.

Historically, the first form of social consciousness is moral consciousness, without it humanity could not exist even at the earliest stages of its development, as moral norms reflecting the basic values of a society are the most important regulators and stabilizers of

${ }^{*}$ Corresponding author: dinamism@yandex.ru 
any social relationships. In the conditions of a primitive society, two more forms of social consciousness arise they are aesthetic and religious. It is considered that religious consciousness develops later than aesthetic and, accordingly, moral, with which, however, representatives of the institution of religion argue, claiming the primacy of religion in relation to morality and art. Further, as a society develops, political consciousness is formed and then - scientific consciousness. Certainly, the listed forms are not final and the only ones. The development of the social system continues, and it leads to the emergence of new subsystems in it, requiring their own understanding and, consequently, generating new forms of the spiritual sphere of a society.

In the works that have appeared in recent years, the topic of the formation of the spiritual culture of the individual is investigated in the philosophical, ethical, ecological and sociological aspects Elizabeth J., Tisdell, Divisenko K.S, Belov, A.E., Aaron B. MurraySwank, Kelly M. McConnell \& Kenneth I., Niko Kohls, Harald Walach \& Markus Wirtz, Zhang, K.C., Hui, C.H., Lam ,J., DiReda J, Gonsalvez J., Underwood, Lynn G., Wills, E., Yartseva, V.P., Ganieva R.H., Plotnikova E.Z., Sedankina T.E., Sharipova, E.K., Kedeibayeva, Zh. and Kurbanbayev, K.

The spiritual sphere, being a subsystem of a society as a whole, reacts to all changes occurring in its other subsystems: economic, political, social. Therefore, sharp economic changes could not affect the state of the spiritual life of the country. Many researchers focus on changes in the value orientations of people, an increase in the importance of individualistic values. There is an acute problem of the commercialization of culture and the associated problem of a decrease in the level of its artistic value, as well as the lack of demand for classical cultural samples by the mass consumer. These and other negative trends in the development of domestic spiritual culture can become a significant obstacle to the progressive development of our society.

Elizabeth J. Tisdell consider that today, social and humanitarian knowledge and enlightened public consciousness begin to assess the scale of cultural losses suffered by the world more adequately, and this has acquired an over- urgent character for our society due to the cultural degradation and massization recorded in it, the devaluation of the highest spiritual values [1].

Modern society consists of contradictions caused by the confrontation between the innovative and the traditional, the collective and the individual, the spiritual and material competition for primacy in the value system, nostalgia for the past and the need to move towards the future on other principles of organizing socio-political relations, etc. There are also questions, contradictions, dilemmas in the relation to the development of the spiritual sphere. K.S. Divisenko and A.E. Belov in their scientific works they say on the one hand, certain forms of activity were detached in the world, their release from the rigid ideological and moral dictate, but, on the other hand, the coordinates of Good and Evil, which determine the forms and content of social practices and interactions, remained undefined [2].

Moral deficiency and moral inconsistency of modern society form the need to create various "cult figures" and a kind of surrogate samples of "morality". The evaluate of sociocultural crisis in the post-Soviet countries suggests that the potential for self-development of society in the existing sociocultural format has been exhausted. The era of a general socio-cultural crisis has come, and this manifests itself in the destruction of a society and its culture and, above all, in the destruction of the spiritual world of the individual.

In these conditions, spiritual impoverishment as the advancement of a person and society towards primitive and low spirituality in the processes of sociocultural changes and its manifestation in the world of values and communicative-behavioral social practices acquires the status of an urgent scientific problem. The opening of the borders of the sociocultural space after the collapse of the Soviet system, as well as the impact of 
globalization, stimulated the growth of opportunities for sociocultural choice, due to the rapid involvement in global networks for the exchange of information and intellectual resources. Western consumption patterns and cultural patterns have poured into our society, gradually replacing their own cultural and historical traditions and patterns of behavior.

Aaron B. Murray-Swank, Kelly M. Mc.Connell and Kenneth I. Pargament considers at the same time, such valuable qualities of "human capital" as independence, criticality and creativity of thinking, realism in assessing reality, initiative and high individual responsibility, high adaptability to rapidly changing reality as the basis of social mobility and success are gaining importance in the social space. It is determined both by the need to adapt to the new social order of the capitalist type, and by the strategy of modernizing society and overcoming the protracted socio-economic and socio-cultural crisis [3].

G.A. Avanesova, A.N. Arlychev, P. Bavina, A.V. Botvinova, I. Gundarova, A.V. Zakharova, A. Yu. Zudina, JL.A. Konevskikh, R.L. Livshits, A.K. Uledov and others devoted their works to the study of the spiritual sphere of society and spiritual culture in its various aspects. S. B. Tokarev draws attention to the fact that the multidimensionality of the spiritual life of society is associated with the differentiation of ideals and values and is the result of the objectivity of our consciousness, and hence the various interpretations of spirituality, the parameters of its measurement, the criteria on the basis of which the experienced spiritual experience is assessed.

S.I. Bokachev considers spirituality as a form of mastering social experience, a determinative-imperative component of human existence, an analogue and content of a person's creative mission.

The socio-philosophical level of the study of the concept of spirituality in the context of various spheres of spiritual life and the identification of types of spirituality can be traced in the works of V.C. Barulina, S.B. Krymsky, V.G. Fedotova and other authors.

I.A. Bokachev, A. Ya. Kanapatsky and other researchers consider the ontology of spirituality. A number of authors investigate the problems of spirituality and humanism. These are the works of O.V. Afanasyeva, V.C. Barulina, Yu.G. Volkova, Yu.V. Evdokimova, M.S. Kagan, L.I. Kazakova, T.I. Kostina, P.V. Simonova, V.P. Tugarinova, A.K. Uledov and others.

\section{Materials and methods}

Each historical epoch inevitably returns to the consideration of problems that are usually called "eternal". The actuality of their analysis arises because these old problems remain eternally new. Behind the external familiar and traditional form, they conceal a new and unique content, born of new living conditions. Niko Kohls, Harald Walach and Markus Wirtz considers they are especially acute when it comes not only about social processes, about the problems of the development of civilization, but also about the person himself, who currently has unprecedented power over his own destiny and the fate of the entire planet. This is quite understandable, because interest in these problems is generated every time by new social conditions in which a person lives and in which his activities take place [4].

Each historically specific society is organically associated with a specific person, his views and attitude, deeds and actions. Modern processes in the country are confirmed as obvious: any reforms can be successful if they are centered on a person with his real problems; he is both the object and the controlling subject in solving the entire complex of complicated and urgent tasks, as well as the goal and means of transformations in all spheres of society. In addition, the problem of a person in radical social transformations conditions is the problem of his personal self-determination, self-awareness and spiritual renewal. And these are already questions of the worldview, ideology, value orientations, the 
development of adequate concepts of the vision of life, the creation of an integral education system that would correspond to the modern stage of social development.

In this case, one of the problems, which throughout the entire history of philosophical thought has not ceased to be in the focus of attention of philosophers of various directions, is the problem of spirituality, which has not only great theoretical, but also practical significance. K.C. Zhang, C.H. Hui, and J.Lam in scientific works, they emphasize it is especially actual for today's situation, when our society has to find its way into the future, morally improve the public and private life of the citizens. The increased interest in understanding spirituality itself and the problems of its implementation is determined by a combination of objective and subjective reasons [5].

Today all spheres of human life and activity are affected by a systemic crisis. One of its fundamental reasons is the entry of the human community on the dangerous path of ignoring the spiritual essence of culture. This led to a fatal outcome, when its material side is developed much more strongly than the spiritual, as a result a certain balance was disturbed between them with all the ensuing consequences.

The nature of the manifestation of cause-and-effect relationships and interdependencies in the dialectic of the material and spiritual is extremely multifaceted and ambiguous for explanation. But the general situation here obliges in a timely manner to generalize and deepen ideas about the essence of changes in each of the parties, the nature of their interaction in the dynamics and statics of the real life of society and the individual, and on this basis to substantiate ideas, directions and "technologies" of reproduction and development of spiritual foundations in all forms being a person. J. DiReda, J. Gonsalvez considers in turn, when the criteria of spirituality more and more powerfully declare themselves in the changing conditions, the consideration of the spiritual and the problems of its implementation requires a rethinking of methodological, applied, theoretical and methodological issues directly related to the solution of the spiritual means of specific tasks facing society [6].

It is possible to consider the fact that with an obviously insufficient elaboration of the concept of a national idea and programs for carrying out reforms, market mechanisms come into active action. This creates conditions for a more active manifestation of forms of spiritual freedom of the individual, its choice of social actions, occupation, and the realization of her creative abilities. At the same time, more and more carriers and strata of various forms of property are being "reproduced", generating "their own" (often anti-social) ideology and orientation. As a result, along with the expansion of opportunities for spiritual enrichment and self-determination of the individual, negative processes are growing like an avalanche, which manifests itself in the loss of moral guidelines, an increase in crime, drunkenness and drug addiction. We can say that a free, but socially ill-mannered "spirit of individualism", selfishness and lack of spirituality burst onto the surface of public life, crushing the age-old wisdom of generations on the way, devaluing such concepts as honor, conscience, love, duty and others. This creates the danger of an anthropological crisis and creates a distinct threat to the social and spiritual security of society.

It should be said about the prerequisites of the socio-cultural situation, which in the future tends to become significantly worse, as market laws come into force and the need, as some scientists try to assert, not for a comprehensively developed, but for a "market" personality. Such market personalities have to satisfy one condition: they have to be in demand. A person is no longer interested in either his own life or his own happiness, he is only concerned about not losing the ability to sell. Such views and points of view are not isolated. According to them, the need to educate a person, spiritual renewal of the individual and society is practically rejected.

Underwood, Lynn G. consider at the same time, the spiritual situation in the country clearly confirms: any reforms can be successful if the person stands in the center of them as 
a measure of all things, when it is taken into account that in conditions of radical transformations one of the main problems for him is the problem of personal selfdetermination and self-assertion in the course of his activities, where, in fact, he realizes his essential forces, focusing on this or that public recognition. And these are the issues of the formation of the spiritual world of the individual, its worldview and value orientations, where it is important to take into account: a person from the proposed by a society from the standpoint of his capabilities and their implementation chooses not results, but means of activity, not "things" but processes, not standards and space for the application of their forces. Therefore, a vision of the spiritual meaning, an understanding of the essence and role of the spiritual foundations of human life seems necessary in the search for a way out of this situation. Today, it is important to understand the possibilities of a society to influence on a person, some how change his spiritual world, learn to influence on him, build a different system of prioritiesinhim [7].

Today it is no longer enough to be limited to, for example, updating the moral, aesthetic, legal, or any other type of education. Time requires a search for holistic foundations in the implementation of the goals of the formation, development and education of people, especially youth. Such a basis is spirituality, as a synthesis of everything that distinguishes a person from a person and with the help of which and on the basis of which people are "made" people. Spirituality largely determines the extent to which a person can dispose of endowed abilities, how correctly he can subordinate his mind, needs and coordinates his actions with reality, the objective course of historical development.

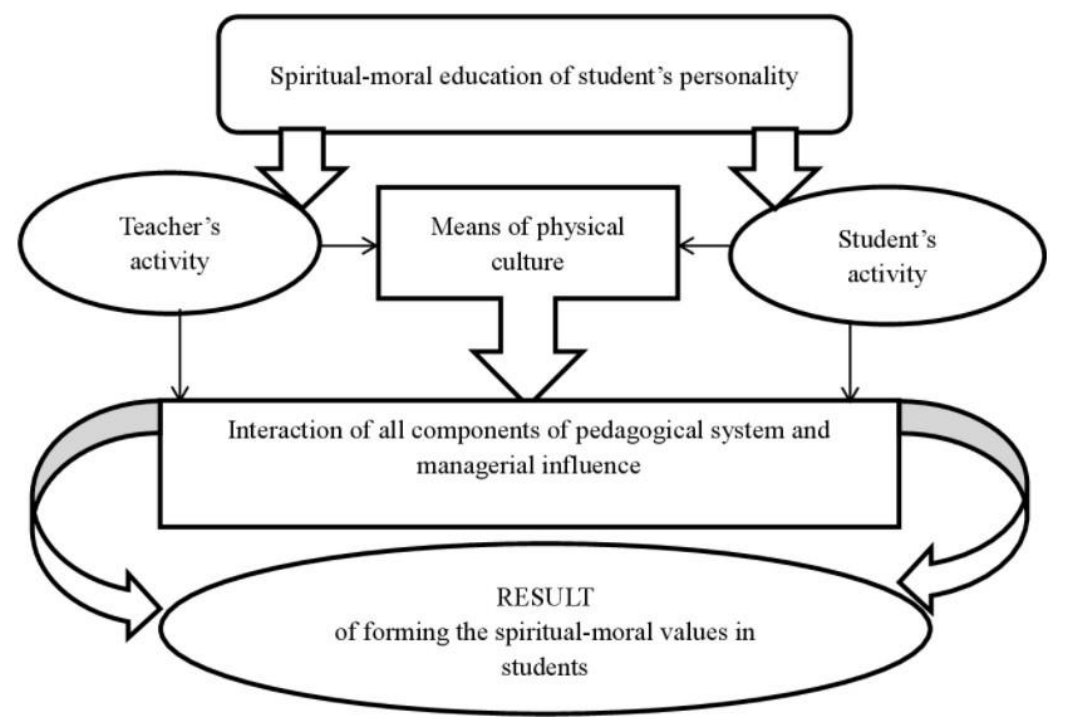

Fig. 1. System of forming the spiritual-moral values of students by means of physical culture.

Thus, we are talking about the creation of a unified theory about a person, and, accordingly, about the development of technologies for managing spiritual processes that would originate from the essence of a person and would be built according to the nature of implementation in the name of the actual development of a person and his potential in a particular area activities. Without all these, the worldview base will remain weak and incapable of ensuring the implementation of constructive policies in the broadest areas of social transformation - in science, art, management, economics, demography, and so on.

E. Wills in works emphasizes that today, more than ever before, that research ideas are needed that would conceptually incorporate everything essential about a person (who in 
fact is always the object and subject of research for social philosophy), as well as everything that surrounds a person and creates him. The most important fundamental idea for research is the idea of spirituality, which plays the role of an initial central core in the methodological functions of studying a person and society [8].

Philosophy and other social sciences and humanities currently have extensive material on research topics. Despite the ideological commitment at certain periods of the development of the problem, and often ideological interpretations of certain ideas about spirituality and its implementation in various activities, the achievements in this area of science are undeniable. In the 1920s and 1930s the problem of the spiritual was most actively comprehended. Then, for obvious reasons, it was ousted and "pushed aside" by the official ideology to the background. New interest of spirituality aroused among representatives of various socio-economic and humanitarian disciplines only in the $60 \mathrm{~s}$. The period of the 80 s-90s can be called a kind of renaissance. It was a time of searching and developing new approaches to understanding the issues of human upbringing, managing his social orientations in the context of reforming all spheres of social life.

V.P. Yartseva consider a distinctive feature of the philosophy of this period in the study of the spiritual is the accentuation of problems in the context of the real life of a person and society. This was found a refraction in the "universal" spirit of the best works of art, the expansion of the humanitarian content of politics, ideology, spiritual life, systems of education and upbringing, society as a whole [9].

In recent years, a significant number of works have appeared in the literature, the authors investigate certain aspects of spirituality, considering it from different angles. Among them there are works devoted to the study of the essence of the spiritual and various aspects of its manifestation and functioning in the life of the individual and society, as well as the conditions and factors for the formation and development of the spiritual world of a person. In them, along with the analysis of the main issue, it is considered separate aspects of knowledge about a society and man.

It can be asserted that by now scientists have achieved certain results in the study of the fundamental foundations of spirituality, the development of its categorical apparatus from the standpoint of modern domestic and world science, the creation of a unified concept of the spiritual, in the study of its place and role in the system of spiritual processes occurring in the country and the world in general.

Noting a significant amount of literature on the problems of the spiritual and the nature of its manifestation and functioning in the life of a society and the individual, it should be noted that the understanding of the category of "spirituality" today does not have a sufficiently definite interpretation, and some important issues are still generally out of sight of researchers. Modern theory and practice cannot be satisfied with the provisions on the spiritual, the interpretation of which does not depend on the essence of the issue, but on the adherence of this or that author to this or that method of research, to this or that worldview, ideological, political orientation, which gives a picture where every an educated person recognizes the existence of the spirituality of a person, but modern human science still does not give clear answers to what its essence is, how it manifests itself, how to develop it, and even more so how to manage it [10].

As a result, there has been developed a paradoxical dilemma between the volume of material on spirituality and the quality of its implementation in philosophical thought. Analysis of the literature shows that the latter does not meet the requirements of the time, the tasks of the theoretical and practical work of a society in the systems of education and upbringing, in preparing the individual for mastering reality. When it comes to the practical 
side of things, calls for spirituality are concealing a disregard for concrete life, for the nature of things, a tendency to replace them with information. In this case, hopes for spirituality become a screen for this process. Therefore, we are talking not only about the theoretical, but also the practical side of the problem, about a more substantive understanding of what "must be taken" in the spiritual and how to implement it in specific types of human activity.

R.H. Ganieva in her scientific research, she states the category "spiritual", as a concept, has an independent meaning and it is intended to "cover" all aspects of the manifestation and functioning of integral human (as opposed to animal) activity in its socio-cultural determinism and content. This approach meets the requirements of the modern situation, when the need for spiritual renewal and development of a man and society has become not only a real fact of life, but also one of the fundamental conditions for the advancement of a society in the direction of progress. Following it opens up broader opportunities for studying spirituality as an independent social phenomenon, which means that with due certainty it allows us to reveal the objective vision of its essence [11].

The spiritual and moral crisis, which today engulfs all spheres of a human life and activity, is one of the fundamental reasons for a society to enter the dangerous path of ignoring its spiritual essence. It is known that a person's life, regardless of the sphere of manifestation of his activity, takes place in the bosom of dialectical interaction between material and spiritual. And if the material is the basis for the development and functioning of the essential (generic) forces of a person, then the spiritual, in the broadest sense, can be defined as the highest form of social reflection, in which the system (set) of dominant ideas, meanings, motives, interests, goals is projected and focused, values, as well as mechanisms for their implementation in the spiritual world of man. The qualitative side of the positively spiritual, mastered by the personality, is recorded in the category of "spirituality". The path of spiritual development is interpreted as "ascent" along the path of gaining truth, goodness, beauty and other higher values.

Spirituality as a personal quality is formed indirectly (under the influence of the entire complex of macro and microconditions and factors of the developing social reality) and directly in accordance with the requirements of the era and society. Therefore, real changes for the better in the spiritual sphere are possible only in the event of radical changes in the socio-economic sphere. The general instability of the socio-political and nationaldemographic situation, serious economic difficulties, negative social consequences of the transition to market relations, the high cost of goods and services, inflation, unemployment and forced migration led to a significant decrease in the living standards of the majority of the population, an increase in the gap between average per capita incomes and subsistence minimum, the growth of categories of disadvantaged and conflict families, families with children below the poverty line, and more. At the same time, radical changes took place in the system of education, upbringing, enlightenment, culture, the functioning of a number of social institutions related to the education, upbringing and socialization of the individual was disrupted. Therefore, in solving economic, political, legal, scientific, educational and other problems facing society, it is always important to know the features of the changes that have occurred and are occurring in the spiritual sphere at the level of the universal, general, special and individual. E.Z. Plotnikova consider that accordingly, in each specific historical period, era, it is important to determine the choice of the dominant sphere in the spiritual world of a person, with the help of which and through which it is possible to exert the most optimal control effect on the nature of his spiritual renewal. In modern conditions, it is the sphere of values and evaluation [12].

The predominance of negative consequences of the spiritual and moral crisis of the personality creates a situation when a person begins to alienate not only from his culture, social institutions, but also from his own essence. In this regard, in the process of spiritual 
renewal of the personality, it is necessary to take into account the humanistic criterion of social development, which intends the exercise of real rights of the individual, and not their abstract declaration. This will give an opportunity to individuals to engage in new models of behavior voluntarily, as they realize their personal advantages from introducing new values, that is, it is necessary to provide the individual with a certain freedom of choice.

At the end of XX - beginning of XXI centuries, the virtualization of the socio-cultural space as a substitution of reality in the new communication system leads to a transhistorical splitting of the "triennial" (cognitive, moral and aesthetic principles) in the spiritual world of a young person, which leads to a spiritual crisis, and a temporal splitting of mental time, the "scattering" of the past and the future in the present increases the possibility of manipulating the youth consciousness.

The transformation of the spiritual world of a modern young person is carried out under the influence of two parallel factors: meaning-forming and instrumental. At the beginning of the XXI century, spiritual culture becomes the leading factor in the formation of meaning in the spiritual world of a person and acquires the meaning of a humanitarian intellect, capable of providing a technical and humanitarian balance that guarantees the continued existence of modern civilization. T.E. Sedankina consider the state youth policy as an instrumental factor in the transformation of the spiritual world ensures the viability of youth, manages the process of "connection of times" and creates conditions for the development of the innovative potential of the young generation in the interests of a society [13].

The transformation of the spiritual world as a socio-cultural strategy is provided by a special "technological equipment" in the form of self-determination and self-affirmation, acting as social mechanisms. Self-determination as a type of cultural and value dominant is based on the perception and use of ideals and values, which contributes to the formation of the integrity of the spiritual world. Self-affirmation as a cultural-activity dominant contributes to the formation of a culture of individual behavior and a culture of collective activity.

The splitting of the spiritual world of a young person gives rise to an anomie of spirituality of youth, which is overcome under the influence of spiritual and moral immunity, which ensures the integrity and immunity of the spiritual world of a young person to an alien mentality by selecting information that meets the requirements of modernity, spiritual resistance to the requirements of irrational everyday life and by climbing to modernity as the unity of the past (continuity) and the future (potential expediency) in the informational field of culture .

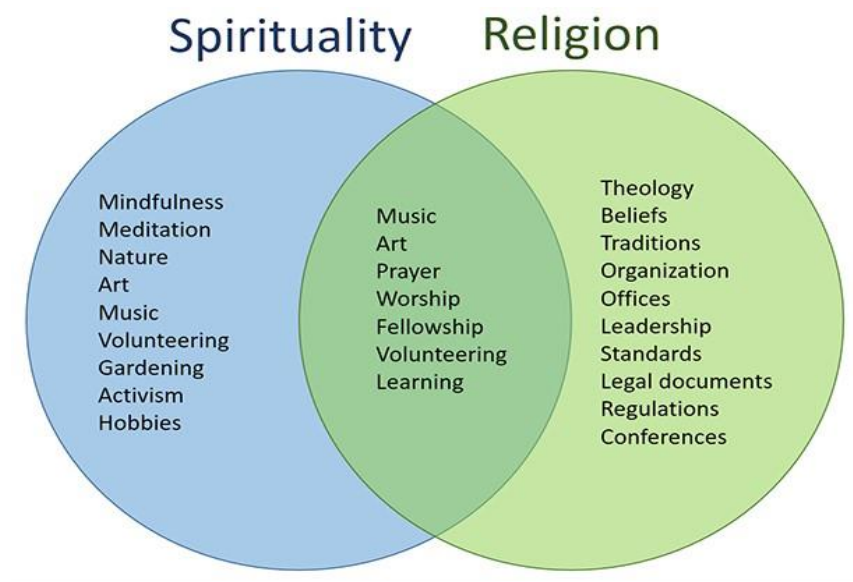

Fig. 2. Spirituality versus Religion. 
Culture in general, and spiritual culture in particular, organizes the content of elements of political culture, moral culture, economic culture, legal culture, and aesthetic culture. These elements of culture are formed and developed along with the enrichment of the life of the individual and society. In turn, the increasing the elements of culture is enriched by a close relationship with the socialization of the individual in the process of improving the individual. The orientation of the goal of the individual's activity will become known in the further formation of beliefs in the worldview of the individual. Each person in the society has his own special beliefs, views on which the formation of a humanistic type of improving the spiritual culture of a person is based. Thus, the individual develops national, religious and universal values, such as humanity, patriotism, interethnic harmony, religious tolerance, and mature political consciousness. E.K. Sharipova, Zh. Kedeibayeva and K.A. Kurbanbayev in their scientific research, they claim the formation of the spiritual culture of the individual, its enrichment by socialization, continues to be complicated by the importance of each social system, in a certain political influence. For example, during the former Soviet system, the spiritual culture of the individual was filled with communist content and was subordinated to the ideas of collectivism, equality, while national and religious values were completely ignored. Under these conditions, the spiritual culture of the individual did not only develop, but also the spiritual freedom was limited [14].

The issue of the spiritual culture of a person seems to be a wide-ranging philosophical category and therefore, all its processes are not so easy to describe. The formation of a person's spirituality is, first of all, enriched at the expense of objective and subjective factors inherent in the development of human history. This is a socio-economic, spiritual and moral way of the development of a society. In particular, in this historical process, national and religious values form the basis of spirituality. It is known that every person who comes into the world, from the beginning to the end of his life, absorbs the specific features of his region, customs, traditions, conditions and rules of individual and social life, all these values are of great importance for a man and humanity. The person always feels the influence of their educational orientation. Also, "the historical formation of these values will be significant for all phenomena of a man and humanity".

In every person, the formation of spirituality is based on his material and spiritual needs. For example, a spiritual need, in the opinion of most scientists, based on education, it is enriched by heredity (writers, artists, sculptors and owners of other professions have such abilities). However, in our opinion, the existence of individual abilities in each person develops a person's spiritual culture and requires tireless work, constant improvement of hereditary and acquired abilities. The subject in this typical process of life is not only individualized, but together with this individualization, in a certain sense, is generalized.

The theoretical foundations for the formation of personality spirituality were laid by such outstanding scientists and philosophers as Socrates, Plato, Aristotle, I. Kant and others. These scientists considered the problem of the relationship between the individual and society or the place of the individual in the society. In this aspect of considering the personality, the main emphasis was on harmonizing the individual and social in the personality, spiritual and material principles. Especially the problem of the spiritual principle in the personality has become the main one in ancient philosophy since the time of Socrates. It was Socrates who linked the vital necessity of the spiritual culture of the individual and its constant improvement with the course of the entire life of the individual. Modern philosophers and researchers of the problem of the spiritual culture of the individual basically update the views of ancient thinkers and adapt them to these conditions.

The scientific understanding of personality in its inner formation also has a system of religious philosophy. If in the philosophy of the ancient period the main emphasis was placed on the spiritual principle of the individual himself, then in medieval philosophy 
there is a turn towards a supernatural spiritual principle. For example, in the teachings of Christianity, spirituality is understood as a synonym for supernatural spirituality, "individual substance", features of the mind, immaterial spirit, as a part of the divine in a man.

R. Descartes who is the philosopher of modern times expressed the idea of a dualistic principle in a man. According to the German philosopher I. Kant, the spiritual principle in a man sets us apart from the animal world. The English philosopher J. Locke singled out the ability to "think reasonably" in a person as a manifestation of spiritual culture.

As in the West, the idea of the spiritual culture of the individual was in the center of attention of Eastern thinkers in the East. In particular, scientists from Central Asia devoted a significant place to this phenomenon in their works. Initially, the concepts of spiritual culture were contained in the sacred books of the peoples of this region - the Avesta and the Orhun inscription.

Spirituality differs from religiosity in that the source of the latter is the external world in the form of prescriptions and traditions, while the source of spirituality is the inner experience of a person. It can also be said that "spirituality is the ability to transfer the supermarket of external being into the internal universe of the personality on an ethical basis, the ability to create that inner world, thanks to which a person's identity is realized, his freedom in front of constantly changing situations. Spirituality, ultimately, leads to a kind of semantic cosmogony, the combination of the image of the world with the moral law of the individual."

The study of spiritual culture requires a distinction between the definitions of spiritual life, public consciousness, spiritual culture. The fundamental work on these theoretical issues remains the monograph "Spiritual life of society: Methodological problems of research." by A.K. Uledovaю The candidate analyzes this work, and considers the position of A.K. Uledova that spiritual culture is not only a set of values, but also an active creative activity of people, such as the production, storage, distribution and consumption of spiritual values. The content of spiritual life and spiritual culture has been constantly refined and changed, so recently the dominant opinion is that spiritual life includes spiritual culture.

Based on the theoretical premises of A.K. Uledov, the candidate comes to the conclusion that spiritual life and spiritual culture in sociological terms is not reduced to a set of ideal phenomena, but it is characterized as a more meaningful formation, which is characterized by social institutions engaged in spiritual production and distribution of its products, social carriers of the spiritual.

In the sociological tradition, as a rule, culture is identified with a set of norms, ideals that perform the function of social orientation. In this context, culture is a system of values, ideas about life and behavioral codes inherent in a given society or large social group (N. Smelser). Culture, on the other hand, includes individually exceptional actions and motives, creative accomplishments, which in their essence go beyond the social system, acquire historical or moral significance for other generations. The spiritual culture of an individual is the degree of a person's perception of the culture of society, a qualitative indicator of how deeply and organically cultural and moral requirements have been embodied in their activities (educational, leisure, social, political) based on the formative influence of society and educational institutions [15].

In our opinion, methodological principles of M. Weber, his idea of "sociology as an empirical science of culture"should determinesociological approaches to the study of cultural processes. The task of the sociology of culture can be formulated as a comparison of the collective levels of semantic structures that are significant in relation to systems of action, with certain social conditions, the disclosure of their own dynamics. These semantic constructions are "social facts". Along with the concept of the subjective meaning of action, 
which is an integral feature of social behavior, the subject of sociological analysis is the whole variety of ideas, opinions, beliefs, perceptions, images of the world, which together make up what was called representative culture.

Culture is a whole system; it has a certain hierarchy of relations. The candidate for the degree examines the relationship between the concepts of culture and subculture in relation to the concept of norm, sharing the main provisions of Yu.M. Lotman, as a culturologist with the closest understanding of the impersonal mechanisms of culture and personality to sociology as the intersection of social codes. Any culture begins with the division of the world into internal ("their") space and external ("them"). Based on the concept of the border in the sphere of culture (Yu. M.Lotman), it can be argued that culture creates not only its own type of internal organization, but also its own type of external "disorganization". Moreover, the border is like a membrane, and its function is reduced to limiting the penetration, filtration and adaptive processing of the external into the internal.

\section{Results}

Measures contributing to the development of the culture of a person, in our opinion, can be divided into two blocks. The first block is the formation of a nationwide ideology, corresponding to the focus on the interaction of generations, government measures that allow students' youth to realize themselves in cultural creativity. The second block is measures to expand the access of young people to education, to avoid the "closure of the educated class," returning to education the largely lost role of a social elevator.

Measures in the sphere of the spiritual and moral relations and supporting youth culture:

1. The orientation of the authorities towards spiritual renewal, the development of a society and man in his individuality on the basis of the centuries-old culture of the country should include state youth policy as an integral part.

2. It is necessary to approve in the mass consciousness the integration model of a reformed society; for students this task can be solved through the institution of education.

3. Carrying out a balanced state policy which is contributing to the stabilization of interethnic and interfaith relations, the removal of the opposition of cultures is, among other things, a constant gap in upbringing and education. University curricula should promote cultural diversity literacy.

4. Formation of a system of ideals, norms and values that make it possible to perceive the historical past of the Motherland with an understanding of social processes. Calls for a clean slate set the younger generation against the older one and reinforce the already strong tendency of the younger generation to overestimate the role.

5. It is necessary to expand guarantees of the availability of cultural benefits for students and youth in general, to expand the list of free forms and types of cultural leisure, to provide organizational and financial support for innovative youth projects aimed at reviving spirituality.

Measures in the sphere of education:

1. It is necessary to take real steps to ensure equality of chances for education, which is still only a declaration of the welfare state. To create conditions for the implementation of opportunities for social advancement, it is necessary to pay attention not only to the financial levers of education management. The principle of "money follows the student", which is proposed for reforming the education system, will only aggravate the situation, since solvent students are now concentrated in certain schools and universities. It is necessary to reverse the growing tendency towards caste, which aggravates social and spiritual despair and disrupts the mechanism of cultural socialization.

2. Young people need a new social philosophy that explained the relationship between economic and social change to them. In the meantime, young people, increasingly alienated 
from society, trying to adapt to the current situation only materially, choosing a strategy of survival and adaptation to the detriment of active creative activity that transforms reality.

3. In the educational activities of higher educational institutions, more attention should be paid to the profile practice of students, thereby ensuring the development of a cultural business environment. The problem of practice and employment can be solved by organizational measures.

The spiritual sphere of a society is a system of relations between people, reflecting the spiritual and moral life of a society, represented by such subsystems as culture, science, religion, morality, ideology, and art. The significance of the spiritual sphere is determined by its most important, priority function of determining the value-normative system of a society, which, in turn, reflects the level of development of public consciousness and the intellectual and moral potential of a society as a whole.

The study of the spiritual and moral life of a society necessarily intends the allocation of its structural elements. Such elements are called forms of social consciousness. The social consciousness includes moral, religious, political, scientific, aesthetic consciousness. These forms determine the corresponding subsystems of the spiritual sphere of society, differing from each other, not only in the content and method of cognizing their object, but also in the time of occurrence in the process of development of a society.

\section{Conclusions}

The spiritual sphere as a subsystem of a society as a whole, necessarily reacts to all changes occurring in its other subsystems: economic, political, social. Therefore, sharp economic changes could not but affect the state of the spiritual life of the country. Many researchers focus on changes in value orientations, an increase in the importance of individualistic values. There is an acute problem of the commercialization of culture and the associated problem of a decrease in the level of its artistic value, as well as the lack of demand for classical cultural samples by the mass consumer. These and other negative trends in the development of domestic spiritual culture can become a significant obstacle to the progressive development of our society.

\section{References}

1. E.J. Tisdell, Spirituality, Cultural Identity, and Epistemology in Culturally Responsive Teaching in Higher Education, Multicultural Perspectives 8:3,19-25 (2006) DOI: $10.1207 / \mathrm{s} 15327892 \mathrm{mcp} 0803$ _ 4

2. K.S. Divisenko, A.E. Belov, Social studies of subjective well-being in the context of spirituality and religiosity, Sociological journal 23,2, 51-73 (2017) DOI: https://doi.org/10.19181/socjour.2017.23.2.5159

3. A.B. Murray-Swank, K.M. McConnell, K.I. Pargament, Understanding spiritual confession: A review and theoretical synthesis, Mental Health, Religion and Culture 10:3, 275-291 (2007) DOI: 10.1080/13694670600665628

4. N. Kohls, H. Walach, M. Wirtz, The relationship between spiritual experiences, transpersonal trust, social support, and sense of coherence and mental distressa comparison of spiritually practising and non-practising samples, Mental Health, Religion and Culture 12:1, 1-23 (2009) DOI: 10.1080/13674670802087385

5. K.C. Zhang, C.H. Hui, J. Lam, Personal spiritual values and quality of life: Evidence from Chinese college students, Journal of Religion and Health 53, 4, 986-1002 (2014) doi: 10.1007/s10943-013-9686-1 
6. J. DiReda, J. Gonsalvez, The Role of Spirituality in Treating Substance Use Disorders, J. Psychol. Clin. Psychiatry 6(4), 00365 (2006) DOI: 10.15406/jpcpy.2016.06.00365

7. L.G. Underwood, The Daily Spiritual Experience Scale: Overview and Results, Religions 2, 1, 29-50 (2011) https://doi.org/10.3390/rel2010029

8. E. Wills, Spirituality and subjective well-being: Evidences for a new domain in the Personal Well-Being Index, Journal of Happiness Studies 10, 49-69 (2009) doi: 10.1007/s10902-007-9061-6

9. V.P. Yartseva, Spirituality concept: psychological aspect, Applied legal psychology 1(46), 108-121 (2019) doi: 10.33463/2072-8336.2019.1(46).108-121.

10. E.F.Fayzullina, Spiritual eloquence as a kind of oratory, Islamic Studies 10 (4), 239245 (2017) https://doi.org/10.31162/2618-9569-2017-10-4-246-250

11. R.H. Ganieva, Spirituality as a source of individual resilience: results of psychological research, Islamic Studies 11(3), 649-666 (2018) https://doi.org/10.31162/2618-95692018-11-3-649-666

12. E.Z. Plotnikova, Formation of the foundations of spiritual and moral education, Islamic Studies 7(1),12-17 (2014) https://doi.org/10.31162/2618-9569-2014-7-1-12-17

13. T.E. Sedankina, Soulfulness and spirituality: dialectics of the external and internal, Islamic Studies 13(1), 135-148 (2020) https://doi.org/10.31162/2618-9569-2020-13-1135-148

14. E.K. Sharipova, Zh. Kedeibayeva, K.A. Kurbanbayev, Nature and sources of spiritual danger, Bulletin of Science and Practice 6 (2), 362-368 (2020) https://doi.org/10.33619/2414-2948/51/46

15. R.X.Halitova, The contribution of Islam to the development of culture and civilization, Islamic Studies 7 (2), 89-91 (2014) https://doi.org/10.31162/2618-9569-2014-7-2-89$\underline{91}$ 